\title{
Assistência social e práticas institucionais no atendimento a andarilhos de estrada
}

\author{
Social services and institutional practices \\ provided to highway wanderers
}

\author{
Eurípedes Costa do NASCIMENTO' \\ José Sterza JUSTO²
}

\section{Resumo}

Os andarilhos de estrada se configuram na contemporaneidade como uma das expressões mais radicais de rompimento com os nichos de fixação social, caminhando a pé pelas rodovias do país e, quando de suas necessidades emergenciais, buscando apoio nas instituições assistenciais. Este artigo visa identificar quais práticas institucionais o serviço social realiza com os andarilhos, segundo os relatos de seus dirigentes. A pesquisa foi realizada em quatro instituições assistenciais no estado de São Paulo, por meio de um roteiro de entrevista semiestruturada. Os resultados indicaram que as práticas institucionais do serviço social em relação aos andarilhos envolvem tecnologias disciplinares de poder e saber, mediante procedimentos e regras que impõem a obediência e a vistoria do seu corpo e pertences. É possível concluir que as práticas do serviço social no atendimento aos andarilhos convertem-se em ferramentas estratégicas de poder no controle de corpos e vidas errantes, visando subordinar tal processo de subjetivação às tecnologias disciplinares.

Palavras-chave: Análise institucional; Andarilhos; Serviço de assistência social.

\begin{abstract}
In a contemporary context, highway wanderers can be seen as one of the most radical expressions of a break from socially fixed niches, travelling on foot along Brazil's highways and, when emergency needs must be met, seeking support from institutional care services. This study seeks to identify which institutional practices are provided to highway wanderers by social services, based on reports by managers of such services. The research was carried out at four institutional care services in the state of São Paulo, through the application of semi-structured interviews. The results show that the institutional practices provided to highway wanderers by social services include disciplinary techniques involving power and knowledge applied by means of procedures and rules that impose obedience along with an inspection of their bodies and a search of their belongings. In conclusion, the social service practices that are provided to highway wanderers become strategic tools of power and control over the bodies and itinerant lives, seeking to subsume such a subjectifying process within disciplinary techniques.
\end{abstract}

Keywords: Institutional analysis; Wanderers; Social services.

$\operatorname{rvV}$

${ }^{1}$ Universidade Estadual Paulista Júlio de Mesquita Filho, Departamento de Psicologia Evolutiva, Social e Escolar, Grupo de Pesquisa Psicologia e Instituições. Campus de Assis, Av. Dom Antonio, 2100, Parque Universitário, 19806-900, Assis, SP, Brasil. Correspondência para/Correspondence to: E.C. NASCIMENTO.E-mail: <nascimentoec@gmail.com>.

2 Universidade Estadual Paulista Júlio de Mesquita Filho, Departamento de Psicologia Evolutiva, Social e Escolar, Programa de PósGraduação em Psicologia. Assis, SP, Brasil.

Artigo elaborado a partir da tese de E.C. NASCIMENTO, intitulada "Errância no contemporâneo: um estudo sobre a percepção de dirigentes e profissionais de instituições assistenciais em relação a andarilhos de estrada". Universidade Estadual Paulista Júlio de Mesquita Filho, 2012

Apoio: Fundação de Amparo à Pesquisa do Estado de São Paulo (Processo no 2009/00641-0). 
A errância na cultura brasileira se configura como um fenômeno complexo e multifacetado, na qual os andarilhos de estrada podem ser tomados como um de seus exemplos mais radicais. Trata-se de indivíduos que percorrem longas distâncias a pé pelas rodovias do país, com um saco às costas onde carregam todos os seus pertences (Justo, 1998, 2011, 2012; Justo \& Nascimento, 2005, 2012; Nascimento, 2008; Nascimento \& Justo, 2000; Nascimento, Justo, \& França, 2009). A perambulação pelos acostamentos das estradas acaba se transformando numa forma de vida errante, sem um lugar, sem re-lacionamentos sociais e sem vínculos fixos ou estáveis. Alguns tentam sobreviver fazendo bicos ou realizando trabalhos temporários e eventuais, quando os encontram pelo caminho. Outros já desistiram do trabalho e sobrevivem da ajuda de famílias residentes nas propriedades rurais adjacentes às rodovias, da ajuda de proprietários e funcionários dos postos de serviços, onde normalmente recebem alimentação e permissão para pernoitar em algum recanto ou, então, recorrem às instituições públicas e filantrópicas de assistência, normalmente em situações mais críticas, tais como dias chuvosos ou de frio intenso.

Embora não existam dados demográficos sobre o número de andarilhos nem estimativas sobre o crescimento dessa população, é notável sua presença, sobretudo em determinadas rodovias que se constituem corredores de circulação. No Estado de São Paulo, as rodovias Anhanguera, Castelo Branco, Raposo Tavares, Marechal Rondon e Washington Luís, dentre outras, são importantes corredores de trânsito onde frequentemente se encontram andarilhos caminhando pelos acostamentos, facilmente reconhecíveis pelo andar compassado, o saco ou mochila surrada às costas, ou, ainda, empurrando um tosco carrinho de mão carregado com todos os pertences.

A despeito do tamanho dessa população, trata-se de um modo de vida ímpar e radical quanto às condições de mobilidade, deambulação, errância, desproteção e vulnerabilidade social - e, por isso mesmo, de extrema importância para o conhecimento científico acerca das formas possíveis da exis-

574 tência humana e para a crítica do tipo de tratamento socialmente dispensado a essa e a outras populações e indivíduos que fogem às padronizações e normatizações da vida. A importância da maneira de viver dos andarilhos se torna ainda maior quando tomada como uma variante ou como um extremo da vida atual, bastante pressionada por forças centrífugas que impelem o sujeito a se movimentar, de maneira cada vez mais acelerada, a ultrapassar fronteiras geográficas, sociais, culturais e psicológicas, e a substituir estilos de vida sedentários por estilos de feitio nômade. Portanto, a investigação do modo de viver do andarilho pode se constituir uma importante via de conhecimento do modo de viver no mundo atual, marcado pela compressão tempo/espaço (Harvey, 1992), do que resulta uma aceleração da vida e sua implementação em espaços abertos (Deleuze, 1992).

Contudo, se a celeridade, efemeridade e mobilidade que caracterizam a vida atual têm sido tomadas em consideração, são extremamente raros os trabalhos que focalizam tais condições da vida contemporânea tomando os andarilhos de estrada como referência. Migrantes, viajantes, aventureiros, povos nômades - como os ciganos -, e outras experiências de mobilidade têm sido estudados, mas são raras as pesquisas realizadas com andarilhos de estrada. Levantamentos de publicações sobre o assunto nas bases de dados Scientific Electronic Library Online (SciELO), Psychological Abstracts, Sociological Abstracts, Lilacs, Clase, PsycINFO, Biblioteca Virtual em Saúde Psicológica (BVS-Psi) e Periódicos Eletrônicos em Psicologia (PePSIC) encontraram na literatura estrangeira, em inglês, estudos voltados para os "vagabundos" ("vagrants", "tramps"), "mendigos" ("beggars"), "desviantes" ("desviants"), "forasteiros" ("outsiders") e "sem-tetos" ("homeless"), que não retratam exatamente condições de vida como a dos andarilhos de estrada brasileiros.

As publicações científicas nacionais a respeito dos andarilhos de estrada são apenas as produzidas pelos autores deste estudo, e referem-se a pesquisas que focalizaram a problemática da subjetividade, da mobilidade tempo-espaço, questões sociais da desfiliação e a saúde mental (Justo, 1998, 2000, 2011, 2012; Justo \& Nascimento, 2005, 2012; Nascimento, 2008; Nascimento et al., 2009; Nasci- 
mento \& Justo, 2000; Peres, 2001, 2002; Peres \& Justo, 2005).

Do ponto de vista foucaultiano, a errância dos andarilhos de estrada também pode estar relacionada com os processos de normalização social, cuja finalidade é mantê-los fixados e distribuídos pelos corredores das rodovias, para que sejam possíveis as ações implacáveis do biopoder proveniente do entrecruzamento dos campos de força do saber e do poder, produzindo saberes e verdades acerca dos indivíduos no espaço social (Nascimento et al., 2009). De acordo com Foucault (1984), o conceito de normalização pode ser compreendido como um sistema de intervalos mensuráveis e tem por objetivos qualificar, classificar, avaliar e hierarquizar cada ação do indivíduo para que ele possa ser controlado pelos dispositivos de segurança disseminados por todo o espaço social.

No entrecruzamento desses campos de força, encontram-se dispositivos ou aparelhos disciplinares que impingem, tanto no sujeito quanto no corpo, uma série de procedimentos atrelados a obrigações e deveres, obediência e submissão, com a finalidade de torná-lo dócil e produtivo. Segundo Foucault, o termo dispositivo se refere a "... um conjunto decididamente heterogêneo que engloba discursos, instituições, organizações arquitetônicas, decisões regulamentares, leis, medidas administrativas, enunciados científicos, proposições filosóficas, morais, filantrópicas" (Foucault, 1979, p.244). Nesse sentido, pode-se conjeturar que a assistência social se configura como um dispositivo de normalização a serviço do biopoder na operacionalidade, controle e distribuição das multiplicidades humanas.

No caso específico dos andarilhos de estrada, isso significa dizer que a ação normalizadora opera nessa lógica de funcionalidade e os coloca em movimentação pelas rodovias por ser um lugar onde não oferecem perigo ao status quo social, ainda mais quando podem ser inspecionados periodicamente pelas instituições que Ihes prestam assistência temporária. A errância, aliás, representa aqui a efetividade da norma, pois, no processo normativo o que ocorre é uma equiparação entre coisas contrastantes e esse procedimento possibilita o trabalho de homogeneização e uniformização das hetero- geneidades, garantindo sua continuidade (Nascimento et al., 2009). É nesse sentido que o biopoder expande sua ação nos programas de bem-estar social, profissionalizando o serviço assistencial para servir de ferramenta de manobra aos interesses políticos do Estado, no sentido de manter as estratégias de controle e administração dos corpos na vida em sociedade.

Assim, nem mesmo os andarilhos que vagueiam pelos acostamentos das rodovias escapam inteiramente aos controles e estratégias da biopolítica. A rigor, não se pode considerá-los, romanticamente, como errantes que desertaram completamente das rédeas do sedentarismo e se livraram de todo tipo de constrições e amarras, ainda que pagando o preço de uma vida praticamente nua do ponto de vista de amparos sociais e bens materiais. Até o que se pode entender neles como uma vida errante precisa ser relativizado, porque o que thes é mais precioso e fundamental nessa vida - poder caminhar a esmo na direção que se queira -, está sujeito a controles e monitoramentos. Isso significa dizer que, no mínimo, estão encurralados em acostamentos de rodovias, cercados dos dois lados, sem poderem estacionar por algum tempo, podendo apenas decidir se seguem adiante ou voltam para trás. E, quando recorrem a alguma instituição de assistência social, definitivamente são capturados pelos mecanismos de controle e monitoramento, tal como acontece com animais selvagens que são capturados, examinados, marcados, catalogados e depois devolvidos à natureza.

Com base nessas considerações e nas reflexões de Foucault sobre a sociedade disciplinar e a normalização social, o presente artigo teve por objetivo compreender as práticas institucionais do serviço social no atendimento a andarilhos de estra$\mathrm{da}$, segundo os relatos de seus dirigentes, relacionando-as com tentativas de disciplinarização, normalização e gestão da vida errante.

\section{Método}

Um primeiro aspecto a ser destacado é que, embora tratasse do modo de viver dos andarilhos, a pesquisa elegeu como participantes não os 
próprios andarilhos, mas os gestores de instituições por onde passam eventualmente e recebem algum atendimento - via de regra, refeição, pernoite e um passe de viagem de ônibus para outra cidade. Por essas razões, foram escolhidos como sujeitos da pesquisa os dirigentes das instituições, porque 0 recorte aqui feito trata das práticas assistenciais produtoras de sentidos sobre a vida errante.

Portanto, a maneira como os andarilhos são tratados nas instituições de assistência social e os discursos dessas instituições refletem e produzem o olhar social mais amplo que recai sobre eles, modelando-os e atribuindo sentidos para seu modo de ser e viver. Por isso, interessa saber dos dirigentes de tais instituições como tratam os andarilhos, como avaliam as práticas e serviços que prestam e o que pensam a respeito da vida errante.

O método utilizado nesta pesquisa foi fundamentado numa abordagem qualitativa, pelo fato de ser esta uma das alternativas possíveis para se compreender a maneira como os indivíduos, historicamente constituídos, apreendem a realidade e se posicionam frente a ela produzindo sentidos (Richardson, 2010). A pesquisa contou com a colaboração de quatro dirigentes responsáveis diretos pela administração dessas instituições assistenciais, a maioria do sexo feminino e com graduação em serviço social. A idade dos entrevistados variou de 41 a 56 anos, com tempo de atuação profissional na instituição entre 3 e 29 anos.

A pesquisa foi realizada em quatro instituições assistenciais de diferentes cidades no Estado de São Paulo, sendo duas públicas (Campinas e Ribeirão Preto) e duas filantrópicas (São Paulo e Bauru). A escolha dessas cidades se justifica pelo fato de receberem um número considerável de andarilhos e por estarem conectadas com importantes rodovias que atravessam todo o Estado, como as rodovias Fernão Dias, Dom Pedro I, Washington Luís, Marechal Rondon e o sistema Anhanguera-Bandeirantes. Dentre as instituições filantrópicas, uma é vinculada à igreja católica e funciona desde 1978 na cidade de São Paulo (SP), enquanto a outra é espírita e está em atividade desde 1951, em Bauru (SP). Dentre as instituições públicas, uma está loca576 lizada na cidade de Ribeirão Preto (SP), onde iniciou suas atividades assistenciais em 1989, e a outra está sediada em Campinas (SP), onde funciona desde o início de 1992.

Para a coleta de dados, o instrumento utilizado foi a entrevista semiestruturada, com um roteiro mínimo e questões preliminares previamente estabelecidas. As perguntas iniciais referiam-se à caracterização da instituição (histórico, missão, entidade mantenedora, serviços prestados, práticas de rotina, clientela atendida e opiniões sobre o modo de viver do andarilho). A ordem das perguntas não foi estabelecida rigidamente, e os entrevistados puderam se expressar livremente, acrescentando em suas falas outros temas e assuntos que lhes ocorressem. As entrevistas foram realizadas individualmente pelo próprio pesquisador com os dirigentes dessas instituições assistenciais, após a aprovação formal do Comitê de Ética em Pesquisa (Parecer $n^{\circ} 36 / 2009$ ).

Após a realização das entrevistas, os relatos foram sistematizados por meio da técnica de análise de conteúdo (Bardin, 2011). Essa técnica se justifica pelo fato de considerar os aspectos semânticos mais relevantes (os núcleos de sentido) presentes nos enunciados emitidos pelos entrevistados, visando à compreensão objetiva do fenômeno investigado. Tal técnica de análise consiste, resumidamente, nas seguintes etapas: transcrição na íntegra das entrevistas gravadas; leituras e releituras dos textos transcritos (pré-análise); análise temática e organização do conteúdo em categorias e subcategorias.

\section{Resultados e Discussão}

Vale ressaltar que há várias maneiras de se apresentar a análise das categorias e subcategorias de uma pesquisa qualitativa utilizando a técnica da análise de conteúdo. Assim, dependendo do estilo assumido pelo pesquisador, as subcategorias podem ser analisadas e discutidas uma após a outra ou conjuntamente, no término da apresentação de todos os relatos referentes à mesma categoria. Neste estudo, optou-se por fazer uma discussão de cada subcategoria após a apresentação dos relatos referentes ao mesmo tema. 
Como se trata de relatos de entrevistas, será utilizado o código "D" para designar os "dirigentes" participantes, seguidos de uma numeração indicativa de cada instituição assistencial, de acordo com o tipo de gestão, visando manter o sigilo e o anonimato das informações. Assim, adotar-se-ão as seguintes nomenclaturas: D1 (instituição pública de Campinas, SP), D2 (instituição pública de Ribeirão Preto, SP), D3 (instituição filantrópica de Bauru, SP) e D4 (instituição filantrópica de São Paulo, SP).

Para compreender como se estabelecem as práticas institucionais no atendimento aos andarilhos de estrada, optou-se por explorar alguns temas estratégicos que permitissem descrever o modus operandi dessas instituições mediante perguntas simples, procurando abarcar o conjunto em profundidade. A técnica da análise de conteúdo possibilitou identificar duas subcategorias referentes às práticas institucionais do serviço social no atendimento a andarilhos de estrada: procedimentos institucionais e regras institucionais, analisados separadamente a seguir.

Procedimentos institucionais: os procedimentos que antecedem a entrada dos andarilhos, conforme os relatos apresentados pelos dirigentes, independentemente do tipo de gestão, estão relacionados a uma vistoria completa tanto da bagagem transportada quanto do seu próprio corpo. O poder centralizador atribuído à assistente social sobre a vida desses sujeitos e a decisão de admiti-los na instituição ou encaminhá-los para outras localidades e instituições de saúde aparecem nos relatos sob a forma de triagem investigativa após a vistoria de todos os seus pertences. Exemplos:

Antes de entrarem para o albergue, é feita uma vistoria geral nele e na bagagem que eles mesmos mostram para ver se ele não está portando nenhuma arma ou droga. Então, ele só entra com a roupa do corpo, sem sacola nenhuma e se, às vezes, o vigilante tiver alguma suspeita, ele pede para erguer a camisa. Em caso de suspeita, a gente aciona a guarda municipal. Depois, ele assina um termo de concordância das normas internas, que é lido para ele após a vistoria da bagagem... É feita também uma entrevista com a assistente social que faz encaminhamento para outras instituições de saúde quando a pessoa apresenta algum distúrbio psiquiátrico ou é dependente de drogas psicoativas (D1).

A maioria das instituições que acolhem esses tipos de pessoas costuma ter um procedimento quase que padrão. Por exemplo, é feito uma vistoria na bagagem pela própria pessoa na presença de um vigia que trabalha lá para ver se não tem nenhuma droga ou objetos cortantes. Depois, ele passa pela triagem, que seria uma entrevista com a assistente social, que avalia sua situação e define os encaminhamentos a serem tomados (D2).

Chegando aqui o procedimento é o seguinte: eles têm que tirar tudo o que têm nos bolsos, nós fazemos uma revista nele e nos pertences deles. Então tem uma regra de atendimento: não pode entrar com droga, não pode entrar com cigarro e nem bebida alcoólica. Se eles não quiserem passar por isso, não vão pernoitar aqui. Depois de terem sido aceitos, eles passam por uma triagem com a assistente social, que decidirá o que fazer com sua situação. Então a filosofia da casa é a seguinte: é acolher e, enquanto ele estiver aqui, tentar deixar assim uma lição para eles, uma demonstração de acolhimento com muito carinho, com muito amor (D3).

Todos são revistados e cadastrados numa ficha de identificação. Aqui revistamos todos os pertences para ver se ninguém porta armas, drogas ou objetos perfurantes. Depois, disso, só os pertences de uso pessoal são permitidos carregar. A bagagem fica presa na portaria e é devolvida quando saem da Casa. Esse procedimento é válido para todos que adentram a Casa. Depois disso, eles têm que seguir as normas estabelecidas se quiserem permanecer e receberem o auxílio e a assistência que oferecemos. A partir daí, é feita uma triagem comigo [assistente social] para saber os motivos que 
os trazem aqui e depois a gente resolve o que fazer com ele (D4).

Os procedimentos institucionais apresentados nesses relatos se assemelham muito àqueles observados nos modelos prisionais da atualidade quanto à vistoria dos pertences e às fichas de identificação. Isso evidencia uma "assistência" absolutamente disciplinadora e detentora de saber e poder sobre a vida dos andarilhos e demais usuários dos serviços quanto aos riscos de periculosidade que apresentam para a ordem social. Esses dados também foram constatados em outras pesquisas sobre albergues e instituições assistenciais, que apontaram procedimentos semelhantes ao enfatizarem a ação dos vigilantes na vistoria dos indivíduos e o poder de decisão centralizado na assistente social (Nasser, 2001; Rangel, 1997; Vieira, Bezerra, \& Rosa, 2004).

A vistoria da bagagem e do próprio corpo, de forma generalizada, além de representar uma situação humilhante, espelha para os andarilhos uma autoimagem negativa pelo fato de serem suspeitos de portar armas ou drogas e com isso representarem um risco ou ameaça para os outros usuários desses serviços. Essa suspeita por parte dos dirigentes assistenciais das instituições pesquisadas pode ser compreendida como uma atitude prévia ancorada no imaginário social que associa andarilhos e outros indivíduos estigmatizados a imagens caricatas de vagabundagem e de criminalidade.

São tidos como potenciais produtores de transtornos ou mesmo como ameaça ao espaço interno da instituição, justificando, assim, a revista completa de todos os seus pertences nos momentos que antecedem sua entrada. Tal procedimento só reforça a ideia da discriminação negativa apontada por Castel (2008), segundo a qual o indivíduo é marcado pela aparência que lhe imputa traços de periculosidade e outras características pejorativas, construídas socialmente, e que as instituições disseminam em seus aparelhos operativos, de forma generalizada e homogênea.

Esses procedimentos institucionais deixam claro também que as relações estabelecidas entre os dirigentes e esses sujeitos se pautam na disciplina, através de um pacto implícito que consiste na aceita-

578 ção obediente das regras se quiserem ser assistidos em suas necessidades emergenciais. Isso pode ser verificado nos relatos sobre o momento em que os andarilhos preenchem um cadastro de identificação ou assinam um termo de concordância aceitando por escrito, às vezes, sua subordinação às regras estabelecidas pela instituição assistencial. Esse termo de concordância ou jogo contratual é realizado numa situação de completo desequilíbrio entre as partes, na qual o usuário se encontra em extrema desvantagem. No caso dos andarilhos, eles somente aceitam o contrato proposto porque se encontram numa situação de extrema necessidade, pois, quando não precisam dos suportes mínimos para se manter por si mesmos, muitos evitam o contato com essas instituições (Justo, 2011, 2012; Nascimento, 2008).

A submissão aos procedimentos institucionais contribui para aquilo que Goffman (2003) compreende como exposição contaminadora do sujeito a um mundo completamente diferente daquele vivido por ele na realidade externa com a qual estabelece algum tipo de ligação junto aos territórios do eu, como, por exemplo, seu corpo, sua subjetividade, suas ações imediatas e seus próprios pensamentos. Essa exposição contaminadora aos procedimentos institucionais possibilita, também, a violação da identidade do indivíduo que, ao se subordinar ao jogo contratual, tem a sua história de vida anterior invadida, registrada e arquivada nos cadastros de identificação durante a triagem investigativa.

O poder atribuído à assistente social assume, nessas instituições, o lugar do saber especialista, pois, através da triagem investigativa é montado um dossiê sobre a vida do andarilho, incluindo desde suas últimas procedências até possíveis enfermidades, para que os efeitos da ação normalizadora possam operar objetivamente sobre sua subjetividade. Vale ressaltar que nessa triagem investigativa o andarilho é solicitado a falar sobre si mesmo de maneira semelhante às práticas confessionais normalizadoras apontadas por Foucault na "História da sexualidade" (1988). No caso das instituições assistenciais, parece que o objetivo dessa triagem investigativa é descobrir se o andarilho representa algum perigo à sociedade ou se é portador de alguma anormalidade a encaminhá-lo para tratamento 
específico nas instituições públicas de saúde, com o objetivo de normalizá-la sob o efeito do saber médico objetivante.

A partir desse dossiê, elaborado na triagem investigativa, o andarilho é interpretado, decifrado, avaliado e fixado nos territórios da assistência social, da saúde e da marginalidade, a fim de garantir a operacionalidade da norma e legitimar as ações da biopolítica no controle estratégico e racionalizado da população (Foucault, 2008). Nesse caso, o assistente social ocupa, nessas instituições, a função de especialista médico com capacidade para avaliar cada sujeito exposto à miserabilidade extrema e decretar, mediante a triagem investigativa e os efeitos da palavra, suas condições de periculosidade, normalidade ou anormalidade, além de propor novos procedimentos para disciplinarização dos corpos, caso verifique qualquer resistência ou contraobediência às regras instituídas. Poder-se-ia considerar, então, que esses procedimentos institucionais garantem não somente o saber do assistente social, mas também o poder do Estado no controle e manutenção das desigualdades sociais.

Regras institucionais: as regras presentes tanto nas instituições filantrópicas quanto nas instituições públicas de assistência participantes desta pesquisa estão relacionadas ao cumprimento e obediência aos horários preestabelecidos para alimentação, higiene, descanso e triagem. Dessa forma, impõe-se um rígido controle do tempo e do espaço físico a todos os usuários desses serviços. Em algumas instituições, os próprios albergados são solicitados a contribuir na manutenção da limpeza dos alojamentos e sanitários.

... todos devem obedecer aos horários estabelecidos para banho, alimentação, rouparia e atendimento da equipe técnica. Todo albergado após cinco dias só poderá retornar depois de seis meses para essa instituição assistencial. Eles levantam cedo e tomam café às 7h; já o almoço é servido às onze e meia. Às $16 \mathrm{~h}$ é servido o café da tarde e às 19h30mim o jantar. Depois das 20h30mim é feito o recolhimento nos dormitórios e ninguém pode ficar conversando pelos corredores (D1).
Primeiramente, a pessoa não pode chegar alcoolizada nem drogada, porque aqui não se aceita esse tipo de pessoa. Depois, tem as regras gerais que seria permanecer em silêncio após as 20h da noite, arrumar as camas onde dormem, respeitar os horários das refeições, não arrumar confusão porque senão será dispensado e aceitar o período de permanência que a instituição oferece. Essas seriam as normas principais (D2).

Obedecer os horários programados como café, servido às $7 \mathrm{~h}$, almoço às $12 \mathrm{~h}$, banho das 15 às 17 h30mim, sopa às $18 \mathrm{~h}$ e dormir a partir das 20h. Manter as camas organizadas e na falta de voluntários ajudar na limpeza do alojamento e sanitários. Antes da saída, tem que passar pela assistente social dizendo para onde vai (D3).

Em qualquer organização da sociedade, existem orientações e normas visando a boa convivência. Nessa Casa não é diferente, por isso as orientações e normas foram estabelecidas por uma equipe formada por agentes educacionais, pela assistente social e pelos padres diretores. Basicamente, temos horários que devem ser respeitados, horários para café, almoço e jantar. Não é permitida a entrada depois das 22h, nem pessoas alcoolizadas. Agressões de qualquer espécie e desacato aos agentes da Casa também implicam em desligamento automático. Todo albergado precisa se comprometer em colaborar com a Casa para lavar louças, auxiliar na limpeza, arrumar a cama, manter silêncio e não acender as luzes nos dormitórios... (D4).

Conforme se pode verificar, as regras presentes nas instituições pesquisadas seguem um critério disciplinador que parece diluir as diferenças e catalogar todos os usuários dos serviços assistenciais como indivíduos desamparados e desprovidos de desejo e singularidades, dominados por necessidades básicas de sobrevivência que os nivelam e os reduzem a uma vida mínima de submissão ao poder. Aliás, a disciplina e a obediência a horários são exigências que afugentam os andarilhos dessas 
instituições e acabam contribuindo para fortalecer neles a convicção de que a vida na estrada provê maior autonomia e liberdade, sem impedimentos impostos criteriosamente por essas regras constritoras do comportamento (Nascimento, 2008).

Acostumados às imprevisibilidades e incertezas vivenciadas nos não-lugares assinaladas por Augé (1994) ou nos territórios movediços da errância, os andarilhos não se adaptam aos dispositivos disciplinadores dessas instituições assistenciais e, quando se deixam capturar por elas, é porque não Ihes resta alternativa e, mesmo assim, procuram rapidamente retomar o rumo da estrada. A obediência aos horários, além de representar uma submissão incondicional às regras estabelecidas, pode proporcionar, ainda, uma experiência humilhante nos processos de subjetivação, principalmente quando o poder institucional se apossa momentaneamente da individualidade dos usuários e domina a relativa autonomia que têm sobre si mesmos dentro desse espaço disciplinador (Dornelas, 1997; Nascimento, 2008; Nasser, 2001; Rangel, 1997; Rosa, 2005; Snow \& Anderson, 1998; Vieira et al., 2004).

Segundo Vieira et al. (2004), as regras rígidas, além de imporem aos sujeitos a obediência, têm por finalidade impedir possíveis conflitos entre os usuários, num espaço em que o silêncio se torna uma das características principais, pois evita o mínimo desvio do comportamento e pune os transgressores, servindo, inclusive, de exemplo para os demais não repetirem condutas de rebeldia. Com suas regras rígidas de comportamento e seus horários cuidadosamente estabelecidos para todas as atividades assistenciais, essas instituições reproduzem, portanto, o modelo disciplinar das prisões, tornando a relação com o tempo e o espaço cada vez mais mediatizada, de modo que ninguém escapa à vigilância dos funcionários e ao olho do poder (Foucault, 1979, 1984). A esse respeito, Foucault (1984) esclarece que a obediência rígida aos horários estabelecidos serve também para exercitar as micropenalidades individuais e coletivas, porque a indisciplina precisa ter correções enérgicas e exem580 plares a fim de o poder se exercitar na invisibilidade, com eficácia no controle e vigilância de todos os internos.

Embora as instituições assistenciais pesquisadas não devam ser confundidas com aquelas de total confinamento analisadas por Goffman (2003), algumas características comuns a ambas parecem se fundir, especialmente no tocante às suas regras de funcionamento. O autor observou que, nas instituições totais (manicômios, prisões e conventos), as atividades diárias são rigorosamente estabelecidas em horários fixos, justamente para se obter um controle de cada situação particular apresentada pelos sujeitos.

Desvios de conduta ou desobediência às regras implicam medidas corretivas de ajuste para o perfeito funcionamento do poder e a demarcação dos papéis atribuídos nessas relações. No caso das instituições assistenciais desta pesquisa, esse conjunto de regras também pôde ser verificado nos relatos dos dirigentes, quando mencionaram a obediência como a principal condição para serem aceitos e assistidos em suas necessidades emergenciais.

Assim, o conjunto de regras presentes nas instituições pesquisadas parece ser uma herança advinda das práticas do confinamento eclesiástico analisadas por Foucault (1988) e devidamente aperfeiçoadas na atualidade segundo os interesses políticos do Estado ou da filantropia, cuja finalidade é transformar o indivíduo desprovido do mínimo necessário para sua subsistência em objeto constante e perene da ação normalizadora. Talvez, a única diferença estrutural existente entre esses dois modelos institucionais de acolhimento é que nas instituições totais o sujeito fica confinado por um período relativamente longo (às vezes indeterminado) e, nas instituições assistenciais, o tempo é estrategicamente curto (predeterminado), fazendo com que o usuário se desloque constantemente de um estabelecimento institucional a outro, de uma cidade a outra. Trata-se de uma estratégia disciplinar que não exige o confinamento por longo tempo, mas que é capaz de acompanhar os deslocamentos do usuário, estratégia ondulatória típica da sociedade de controle, tal como foi pensada por Deleuze (1992). 
Pela via clássica da disciplina em espaços fechados ou pelas vias atuais do controle em espaços abertos e de trânsito, a marginalização, a pauperização extrema e a errância radical dos andarilhos de estrada, por exemplo, parecem constituir o corpus vivendi para funcionamento de boa parte das instituições assistenciais que avaliam e classificam esses sujeitos de acordo com seus graus de conformidade ou periculosidade, distribuindo-os por todo o espaço social mediante regras precisas, sutis e eficazes de controle e vigilância através da ação normalizadora. Dreyfus e Rabinow (2010) enfatizam que essa ação normalizadora estará sempre em movimento quando seu objetivo for reunir e catalogar cada aspecto das práticas sociais, a fim de formar um todo coerente para efetivar procedimentos e saberes a respeito da vida de cada sujeito e, com isso, se apropriar de certos domínios para sua intervenção.

Portanto, pode-se dizer que, no interior do espaço físico das instituições assistenciais pesquisadas, há uma tecnologia disciplinadora e correcional sobre a vida dos andarilhos e demais usuários durante o tempo de sua permanência no local. As práticas de assistência às suas necessidades emergenciais acionam mecanismos de controle e vigilância homogeneizadores sobre eles, traduzindo, assim, uma tecnologia bem específica de dominação sem violência. Nesse sentido, submetidos à disciplina e tratados de forma homogeneizante, são obrigados a fazer as mesmas coisas em conjunto, com horários rigorosamente estabelecidos por um sistema de regras que exige sujeição, obediência e um comportamento absolutamente exemplar.

Isso equivale a dizer que as instituições assistenciais desta pesquisa ignoram as heterogeneidades e as histórias de vida dos usuários de seus serviços, pautando suas práticas na normalização social que trata a todos indistintamente, fazendo operacionalizar, assim, as tecnologias políticas na produção de sujeitos dóceis e disciplinados, em conformidade com a ordem estabelecida. Com efeito, pode-se considerar, então, que a assistência social serve como ferramenta estratégica para fixar e distribuir os andarilhos pelos territórios da marginalidade social e com isso ter objetos incessantes para sua intervenção homogeneizante (Nascimento et al. 2009).

As discussões aqui apresentadas abrem possibilidades para se ampliar o debate acerca das práticas institucionais objetivantes. Estas precisam ser discutidas no sentido de produzir outros sentidos para a subjetividade, de forma menos homogeneizante e centralizadora aos efeitos do saber e do poder, respeitando que cada um possa viver de acordo com suas convicções pessoais, mesmo que em condições adversas, como os andarilhos de estrada. Se o Estado tem o dever de assistir aos seus cidadãos em momentos de extrema pobreza ou miséria, por que não pensar em outras possibilidades de assistência menos homogeneizadora e mais solidária, para que todos possam realmente viver a existência, seja ela qual for, de maneira digna mesmo nas condições supostamente indignas?

Assim, uma das questões sociais que se coloca na contemporaneidade é saber como propiciar outras possibilidades de atendimento para que os andarilhos e demais usuários dessas instituições assistenciais tenham melhores condições de serem socorridos nos momentos de extrema dificuldade, sem, no entanto, se submeterem a uma tecnologia disciplinar de docilidade e humilhação. Embora não se tenha uma solução concreta e viável para esse problema sociopolítico, talvez seja o tempo de se pensar, pelo menos, em recusar aquilo que foi imposto há vários séculos como verdade, para poder elaborar outras formas de subjetivação - capazes de produzir um novo sentido à vida e à própria condição humana -, pautadas na ética, no espírito de civilidade e no cuidado de si.

\section{Referências}

Augé, M. (1994). Não-lugares: introdução a uma antropologia da supermodernidade. Campinas: Papirus.

Bardin, L. (2011). Análise de conteúdo. Lisboa: Edições 70.

Castel, R. (2008). A discriminação negativa: cidadão ou autóctones? Petrópolis: Vozes.

Deleuze, G. (1992). Conversações. Rio de Janeiro: Editora 34.

Dornelas, S. M. (1997). O peixe e a rede: o migrante e o albergue no discurso dos responsáveis e funcionários da AVIN. Travessia, 29, 30-45. 
Dreyfus H. L., \& Rabinow, P. (2010). Michel Foucault, uma trajetória filosófica. Rio de Janeiro: Forense Universitária.

Foucault, M. (1979). Microfísica do poder. Rio de Janeiro: Graal.

Foucault, M. (1984). Vigiar e punir: nascimento da prisão. Petrópolis: Vozes.

Foucault, M. (1988). História da sexualidade I: a vontade de saber. Rio de Janeiro: Graal.

Foucault, M. (2008). Segurança, território, população. São Paulo: Martins Fontes.

Goffman, I. (2003). Manicômios, prisões e conventos. São Paulo: Perspectiva.

Harvey, D. (1992). A condição pós-moderna. São Paulo: Loyola.

Justo, J. S. (1998). Errâncias e errantes: um estudo sobre andarilhos de estrada. In R. Y. Sagawa \& J. S. Justo (Orgs.), Rumos do saber psicológico (pp.123-139). São Paulo: Arte \& Ciência.

Justo, J. S. (2000). Saúde mental em trânsito: loucura e a condição de itinerância na sociedade contemporânea. In M. L. Boarini (Org.), Desafios na atenção à saúde mental (pp.9-29). Maringá: EduEM.

Justo, J. S. (2011). Andarilhos e trecheiros: errância e nomadismos contemporâneos. Maringá: EduEM.

Justo, J. S. (2012). Vidas errantes: políticas de mobilidade e experiências de tempo-espaço. Londrina: EduEL.

Justo, J. S., \& Nascimento, E. C. (2005). Errância e delírios em andarilhos de estrada. Psicologia: Reflexão e Crítica, 18(2), 177-187.

Justo, J. S., \& Nascimento, E. C. (2012). Road wanderers in Brazil: A study on modern psychosocial human mobility. International Journal of Sociology and Anthropology, 4(5), 165-171.
Nascimento, E. C. (2008). Nomadismos contemporâneos: um estudo sobre errantes trecheiros. São Paulo: Editora Unesp.

Nascimento, E. C., \& Justo, J. S. (2000). Vidas errantes e alcoolismo: uma questão social. Psicologia: Reflexão e Crítica, 13(3), 109-121.

Nascimento, E. C., Justo, J. S., \& França, S. A. M. (2009). Errância e normalização social: um estudo sobre andarilhos de estrada. Estudos de Psicologia, 14(4), 641-648.

Nasser, A. C. A. (2001). Sair para o mundo: trabalho, familia e lazer na vida de excluídos. São Paulo: Hucitec.

Peres, R. S. (2001). Andarilhos de estrada: estudo das motivações e da vivência das injunções características da errância. Psico-USF, 6(1), 67-75.

Peres, R. S. (2002). O desenho da figura de Machover aplicado em andarilhos de estrada. Psicologia: Teoria e Prática, 4(1), 81-92.

Peres, R. S., \& Justo, J. S. (2005). Contribuições das técnicas projetivas gráficas para a compreensão da personalidade de andarilhos de estrada. Estudos de Psicologia, 10(2), 305-312.

Rangel, M. C. (1997). Migrantes da casa de passagem de Presidente Prudente. Travessia, 29, 17-24.

Richardson, R. J. (2010). Pesquisa social: métodos e técnicas. São Paulo: Atlas.

Rosa, C. M. M. (2005). Vidas de rua. São Paulo: Hucitec.

Snow, D., \& Anderson, L. (1998). Desafortunados: um estudo sobre o povo da rua. Petrópolis: Vozes.

Vieira, M. A. C., Bezerra, E. M. R., \& Rosa, C. M. M. (2004). População de rua: quem é, como vive, como é vista. São Paulo: Hucitec.

Recebido em: 24/1/2013

Versão final em: 10/7/2013

Aprovado em: 22/8/2013 